openaccess

\title{
Escaping Plato's Cave: Ethical considerations for the use of Virtual Reality in psychology teaching
}

\author{
Kristin P.J. Thompson ${ }^{1}$ ๑ 0000-0001-9547-0598, Ciarán O'Keeffe ${ }^{2}$ ๑1 0000-0002-9655-3261, \\ Genevieve M. Cseh ${ }^{2}$ () 0000-0001-5189-2182, Piers Worth ${ }^{2}$ and Matthew D. Smith ${ }^{2}$ ๑ 0000-0002-5133-900X \\ ${ }^{1}$ University of Exeter, ${ }^{2}$ Buckinghamshire New University \\ Corresponding author: Ciaran.OKeeffe@Bucks.ac.uk
}

Virtual Reality (VR) offers exciting new opportunities for teaching psychology, such as the chance to explore questions, phenomena, perspectives and experiences it would be difficult or impossible to observe in the real world or classroom. As VR technology develops, its potential to provide a multi-modal sensory experience may lead to even more immersive environments. With these exciting opportunities, however, come new ethical dilemmas and risks for teachers and students utilising this technology. Many users and manufacturers of VR acknowledge the physiological and psychological impacts of the use of VR (e.g. Sharples, Cobb, Moody, \& Wilson, 2008). One of the most commonly reported effects is motionsickness, however, improvements in technology may help to lessen these. An increasing number of studies are now revealing potential psychological impacts, for example, Aimé, Cotton, and Bouchard (2009) found females reporting increased body dissatisfaction after immersive VR use, and Aardema, O'Connor, Côté and Taillon (2010) found users reporting greater sense of dissociation and lower sense of 'presence' in objective reality. As yet, however, the British Psychological Society (BPS), the professional body for the discipline of psychology, has provided no specific ethical guidelines for the use of VR or Augmented Reality (AR) in research with human participants or in an educational setting.

Our behaviour is influenced by our environment and VR can place students in highly unusual, disorientating environments which can at times create sensations akin to experiences with hallucinogens; these impacts should not be taken lightly, even within informal teaching settings. We aim to address this need within psychology research and teaching, by discussing some potential risks and ethical considerations for educators wishing to use VR in educational settings, including: cybersickness, consensual hallucinations; pressure to conform and power of authority, individual differences in response to VR, and the need for pre and post-use care. Some practical recommendations are presented which also encompass our findings that some pre-use screening tools are insufficient to capture a participant's actual experience and, in some individuals, can prematurely discourage VR usage when in actuality their experience is unexpectedly positive.

"How could they see anything but the shadows if they were never allowed to move their heads?"

Plato - The Allegory of the Cave - The Republic (Book VII)

Keywords: Ethics; Psychology; Teaching; Virtual Reality; Cybersickness; Immersion

Correspondence

Ciaran O'Keeffe (Ciaran.OKeeffe@Bucks.ac.uk)

doi: $10.1255 /$ vrar2018.ch10

Citation: K.P.J. Thompson, C. O'Keeffe, G.M. Cseh, P. Worth and M.D. Smith, "Escaping Plato's Cave. Use of Virtual Reality in teaching psychology: Review and recommendations", in Proceedings of the Virtual and Augmented Reality to Enhance Learning and Teaching in Higher Education

Conference 2018, Ed by J. Hudson and R. Kerton. IM Publications Open, Chichester, pp. 93-99 (2019). https://doi.org/10.1255/vrar2018.ch10

\section{c) 2019 The Authors}

This licence permits you to use, share, copy and redistribute the paper in any medium or any format provided that a full citation to the original paper is given.

Print ISBN: 978-1-906715-30-4 Online ISBN: 978-1-906715-28-1 


\section{Introduction}

The last decade has seen a growth in applications of immersive Virtual Reality (VR) technology across disciplines. Currently, VR is making an impact in psychological research due to a number of methodological advantages it may have over many lab-based experimental psychology practices, in particular, its scope to offer opportunities to lessen the traditional trade-off between environmental control and ecological validity (Kozlov \& Johansen, 2010; Rizzo, Schultheis, Kerns, \& Mateer, 2004). In addition, the study of VR immersion and gaming has become a subject of research in its own right, through growth in commercial availability and recreational use. Furthermore, VR and AR technology is becoming increasingly used in applied healthcare and therapeutic settings (Freeman et al., 2017; Haniff, Chamberlain, Moody, \& Freitas, 2014). With such a wide variety of possibilities, it is becoming increasingly likely that a basic awareness of VR applications in psychology and an understanding of their advantages as research and teaching tools, will become an important part of the psychology student and educator's skill set. However, we must ensure that our understanding of ethics in teaching and research also stays up-to-date with these new technologies. As VR becomes more widely employed as a teaching and research tool, in Higher Education in particular, it is crucial to reflect on VR's unique characteristics-both its opportunities, and its risks.

Here we discuss and review VR as a teaching aid in psychology, with the aim to promote further discussion and research into the use of VR in psychology teaching. We note the unique opportunities afforded by this technology in expanding the repertoire of learning possibilities, but also highlight issues in regard to safe and ethical use of VR within the teaching environment, prompting questions for further research and consideration. We draw on published research, as well as our own experiences of employing $V R$ in the classroom. Although the term VR can refer to several systems, for example, interactive flat-screen or CAVE system, here we tend to use $\mathrm{VR}$ to refer to the head-mounted display system.

\section{Learning and teaching opportunities for VR in Psychology}

Educators are continually looking for novel and creative ways to teach and engage students; VR may appeal in this regard, bridging entertainment and education (Fowler, 2015; Freina \& Ott, 2015). Furthermore, it provides an additional resource for delivering inclusive and innovative teaching methods, perhaps offering an opportunity to individualise learning environments (Bailenson et al., 2008) and offer students more choices and control in their own learning.

Uniquely, VR offers an 'escape' from the limited scope of every-day realities, allowing students and research participants insight into settings and perspectives it is either difficult or impossible to explore otherwise in the classroom or 'real world' settings, allowing for (seemingly) less risky simulation and practice so that students are allowed to learn through trial-and-error, and increasingly the likelihood of broadening of minds. We have found VR particularly useful for providing demonstrations for 'unusual' or conceptually difficult phenomena in psychology, for example, in our module on 'Exceptional Human Experiences' students have the opportunity to explore altered perceptions and altered realities, in a 'safe' and non-permanent environment. For example, a VR space-walk experience has been used to teach students about the overview effect (Yaden et al., 2016), the powerful feeling of awe and shared humanity reported by astronauts gazing down upon our planet from space-not an experience many students are likely to ever have in their lifetime.

We have also used VR to provide students with the opportunity to learn through simulation of real life events in a controlled environment, such as critical incidents, where previously they may have been asked to simply imagine or role-play given the often life-threatening and unpredictable nature of such incidents. Indeed, the use of VR in teaching about all aspects of critical incidents (i.e. training, decision-making, stress and debriefing) within a policing context reflects the merits researchers have previously noted in the use of Simulation Based Training (SBT) for professionals involved in such incidents (Alison et al., 2015). O'Keeffe (2019) comments, for example, on how advantageous critical incident SBT can be in an applied context, including the opportunities to explore the manipulation of influencing variables, the direct observation of adaptability in planning, effective decision management and overall assessment of a range of competencies. In terms of competencies, Paton (2006) notes that enhanced alertness and cognition is achieved through SBT and that the training provides the individual with an important competence, highly relevant in VR 
use, known as situational awareness which is "a capability to operate in complex contexts by extracting just those cues necessary to identify appropriate courses of action" (p. 200). This latter example highlights the advantage of the use of VR in teaching topics without jeopardising the safety and well-being of the participants (O'Keeffe, 2019).

\section{Key challenges in creating a 'VR friendly' classroom experience}

Many users, manufacturers and researchers of $V R$ acknowledge the physiological and psychological impacts of VR, termed Virtual Reality Induced Symptoms and Effects (VRISE) (e.g. Bouchard, Robillard, Renaud, \& Bernier, 2011; Sharples, Cobb, Moody, \& Wilson, 2008). Indeed, these are not to be taken lightly even within informal teaching settings. One of the most commonly reported physical effects is motion-sickness, however, improvements in technology or mitigating methods (e.g. 'anchoring') may help to lessen these (Becker \& Ngo, 2016; Curtis et al., 2015; Fernandes \& Feiner, 2016). An increasing number of studies are now also revealing potential psychological impacts of VR, for example, Aimé et al. (2009) found females reporting increased body dissatisfaction after immersive VR use, and Aardema, O'Connor, Côté, and Taillon (2010) found users reporting greater sense of disassociation and lower sense of 'presence' in objective reality. As VR technology develops, its growing ability to provide a multi-modal sensory experience may lead to even more immersive environments, something which is both exciting and worrying in its regard as a teaching resource. Next we outline key issues and some practical recommendations regarding $V R$ in the classroom.

\section{Cybersickness}

The VR environment provides sensory input that simulates the 'real-word' so much so that participants may experience the virtual environment in a similar way to the physical environment. One of the most commonly reported side-effects of $V R$ is motion sickness, or Cybersickness (and more recently termed VR sickness or VIMS - Visually-induced motion sickness), a term coined to describe the feelings of nausea, body disorientation and dizziness which are frequently reported after $V R$ use (LaViola, 2000). This is thought to be a result of the mismatch between the sensory information received by the participant's perceptual system within VR and the physical environment, for example, where there is optical distortion, or errors in position tracking (Kennedy, Stanney, \& Dunlap, 2000).

Cybersickness is a key ethical and practical concern for users of VR in Psychology teaching. One way to minimise the impact can be to provide participants with information on the factors which may increase their proneness to cybersickness. This could be achieved, for example, through an already established questionnaire such as the Kennedy, Stanney, and, Dunlap (1993) Simulator Sickness Questionnaire (SSQ) or its recent modification by Kim, Park, and Choi (2018) as the Virtual Reality Sickness Questionnaire (VRSQ). There have also been recent developments to mitigate for VIMS by incorporating hand-eye coordination tasks within the VR environment (e.g. Curtis et al., 2016).

\section{Consensual hallucinations}

Virtual reality may have the potential to democratise learning experiences, for example, students can visit anywhere in the world, and even beyond, regardless of physical ability or social status, allowing educators opportunity to teach concepts some students could not experience first-hand, such as remote field trips (e.g. Markowitz, Perone, \& Bailenson, 2018). Furthermore, students can experience alternative perspectives and emotions as if experiencing them in the 'real world' (Diemer, Alpers, Peperkorn, Shiban, \& Mühlberger, 2015). Whilst this offers a potentially exciting opportunity to discuss many topics in Psychology, there may be psychological risks where users are able to immerse in altered states of reality and consensual hallucinations (sensu Mantovani, 1995), that would be considered harmful if occurring in physical reality.

VR allows users to enter an environment where stimuli are synthetically produced, often with the aim to exceed the 'every-day' experience and explore phenomena, places, and experiences from new perspectives-essentially escaping the limited and confined scope of their everyday 'Plato's cave' perceptions. Participants can explore personal and social identities that transcend reality (Rosenberg, Baughman, \& Bailenson, 2013), for example, overcoming physical and biological boundaries such as gender or even species (Won, Bailenson, Lee, \& Lanier, 2015). Technological advances in VR are gradually creating amplified sensory input where the experience becomes fully immersive and interactive using all the senses, perhaps further blurring the lines between reality and simulation. 
For educators using VR to demonstrate and 'induce' altered perceptions and realities to students there is a need to further understand its potential impact, and this may prove to be an important and fruitful area for future research. It is clear that an individual approach to wellbeing during these experiences is needed, as students will vary in coping strategies and responses, much like in the 'real-world'.

\section{Pressure to conform and the power of authority}

There is undoubtedly peer-pressure in any teaching environment and a need to monitor individual differences in any tasks (Kubat, 2018), not least of which are the individual differences in responses to VR. Ethically, supporting individual autonomy can be achieved through Informed Consent and giving participants a choice of experiences and the freedom to withdraw or choose not to participate in the first place. For example, in the $3^{\text {rd }}$ year undergraduate psychology module, entitled 'Exceptional Human Experiences' (EHEs), we encourage students to seek out possible EHEs in a VR environment (e.g. spacewalk, Everest climb, deep sea diving, out-of-body experiences, drug effect simulations, cellular-level rollercoasters, etc.). Autonomy may be 'free-form' allowing individuals to make decisions during an experience. In addition, perceived control, i.e. the ability for the user to instantly remove the VR headset, has the potential to reduce negative responses, such as stress, fear and aggression. For example, GarciaPalacios, Hoffman, Carlin, Furness, \& Botella (2002) examined the use of VR in the treatment of a specific phobia and, in their conclusion, commented on the positive outcomes as being due to the patients' ability to control the feared object in the VR environment. There is also the responsibility in the $V R$ teaching environment to create a 'safe' space. For example, building trust between spotters/operators and participants-creating a safe word to indicate that they wish to end their VR experience, reminding students that participation is completely voluntary, providing alternative experiences for those not taking part, and so on.

There is an overarching concern, however, that where $\mathrm{VR}$ is used in groups or in front of peers, where the majority report an overwhelmingly positive experience, it may reduce the likelihood of students reporting negative impacts (e.g. fear, sickness) during their VR experience, an issue of group conformity (see Asch, 1956).

\section{Pre and post-use care}

Pre-screening can be used in the classroom to determine student susceptibility to problems in VR. This can include screening for both medical and psychological conditions that may negatively impact the VR experience, including phobias, motion sickness (e.g. the aforementioned Virtual Reality Sickness Questionnaire: Kim et al., 2018) and claustrophobia. Students should be given guidance on the type of experience they will have so that they can provide sufficiently informed consent. As students or participants may not have experienced VR before and may not be in a position to imagine the effect it might have based on previous experience, it is essential that they are told explicitly of all known potential effects of the experience and reminded that they should stop/say the extraction 'safe word' if they are uncomfortable for any reason.

Depending on the level of immersion and individual differences, participants will inevitably differ in their VR experiences and their need for after-care. Duration and intensity of the VR activity can cause cognitive, physical, emotional and behavioural disturbances that can last anywhere from seconds or minutes, maybe even days or weeks or longer, once the VR experience has ended (Biocca, 1997; Diemer et al. 2015). Distraction tasks and debriefing could be used to help students safely return to their pre-VR state.

\section{Ethics in the classroom: Ongoing questions}

Psychologists are used to working under a framework of ethical conduct for research. We propose that a similar framework can be used within a VR teaching context to address some of the issues and concerns we have raised above. Basic ethical principles such as informed consent can be drawn from the BPS code of conduct. In addition, we have listed some recommendations for in-class use of $V R$, based on our observations of the use of $V R$ in our classrooms, and related research:

Use of cyber-sickness self-screening tools (e.g. Kennedy et al., 1993; Kim et al., 2018) and other medical questionnaires for students (e.g. history of dizziness/inner ear conditions, or anxiety);

Having trusted spotters present to guide/protect students, agreeing a 'safe-word' to help end the VR session immediately;

Encourage open discussions regarding peer-pressure and cohesion; offer alternative activities for those who choose not to participate to ensure they do 
not feel excluded. Remind students, each time, that participation is voluntary and that not everyone reacts in the same way to VR;

Offer introductory practice sessions to allow students to familiarise themselves with the technology and the frame of reference before beginning any more involved apps or games. Scaffold experiences based on immersion or degree of altered perception involved, so that students can gradually gauge how comfortable they feel as they explore less and less familiar environments; - VR experiences should generally be free-form and autonomous, allowing users to feel in control;

Build BPS research ethics principles into practical sessions and discussions (specifically 'Respect', 'Competence', 'Responsibility', 'Integrity'), including also the use of informed consent, voluntary participation and post-experience debrief (Ethics Committee of the BPS, 2018), and;

Consider what after-care might be necessary if the above safety precautions fail and the student experiences after effects of the experience. What provisions could be made or kept at hand to help ease the discomfort of, e.g., motion sickness, or a severe emotional reaction?

Whilst we draw on our own teaching experiences to adapt and review the above recommendations, there are still many ongoing questions regarding the benefits of VR use in relation to student experiences and learning outcomes in Higher Education, as well as the risks and long-term psychological impacts of VR use. The immersive nature of $V R$ results in objects and the environment potentially being experienced as 'real' much like the shadows perceived as real by the occupants in Plato's Cave Allegory. As use of VR in the classroom becomes more popular, therefore, educators should remain vigilant to the psychological well-being of students using VR, adjusting not simply the health and safety protocol, but continually questioning and debating the broader ethical issues relating to the adoption of $V R$ into teaching practice.

\section{References}

Aardema, F., O'Connor, K., Côté, S., \& Taillon, A. (2010). Virtual reality induces dissociation and lowers sense of presence in objective reality. Cyberpsychology, Behavior, and Social Networking, 13(4), 429-435.
Aimé, A., Cotton, K., \& Bouchard, S. (2009). Reactivity to virtual reality immersion in a subclinical sample of women concerned with their weight and shape. Journal of Cybertherapy \& Rehabilitation, 2, 115-126.

Alison, L.J., ven den Heuvel, C., Waring, S., Power, N., Long, A., O'Hara, T. \& Crego, J. (2013). Immersive Simulated Learning Environments for researching Critical Incidents: A knowledge synthesis of the literature and experiences of studying high-risk strategic decision making. Journal of Cognitive Engineering and Decision Making, 7(3), 255-272. https://doi. org/10.1177/1555343412468113

Asch, S.E. (1956). Studies of independence and conformity: A minority of one against a unanimous majority. Psychological Monographs: General and Applied, 70, 1-69.

Bailenson, J.N., Yee, N., Blascovich, J., Beall, A.C., Lundblad, N., \& Jin, M. (2008). The use of immersive virtual reality in the learning sciences: Digital transformations of teachers, students, and social context. The Journal of the Learning Sciences, 17(1), 102-141.

Becker, J., \& Ngo, T. (2016). Mitigating visually induced motion sickness in virtual reality. Course Project for EE267: Virtual Reality at Stanford University. Stanford University.

Biocca, F. (1997). The Cyborg's Dilemma: Progressive embodiment in virtual environments. Journal of Computer-Mediated Communication, 3(2), JCMC324. https://doi.org/10.1111/j.1083-6101.1997. tb00070.x

Bouchard, S., Robillard, G., Renaud, P., \& Bernier, F. (2011). Exploring new dimensions in the assessment of virtual reality induced side effects. Journal of Computer and Information Technology, 1(3), 20-32.

Curtis, M.K., Dawson, K., Jackson, K., Litwin, L., Meusel, C., Dorneich, M.C., Gilbert, S.B., Kelly, J., Stone, R. \& Winer, E. (2015). Mitigating Visually Induced Motion Sickness: A virtual hand- eye coordination task. Proceedings of the Human Factors and Ergonomics Society Annual Meeting, 59(1), 1839 1843. https://doi.org/10.1177/1541931215591397

Diemer, J., Alpers, G.W., Peperkorn, H.M., Shiban, Y., $\&$ Mühlberger, A. (2015). The impact of perception and presence on emotional reactions: A review of research in virtual reality. Frontiers in Psychology, 6, 26. 
Ethics Committee of the British Psychological Society. (2018). Code of Ethics and Conduct. Leicester: The British Psychological Society.

Fernandes, A.S., \& Feiner, S.K. (2016). Combating VR sickness through subtle dynamic field-of-view modification. IEEE Symposium on 3D User Interfaces, 201-210.

Freeman, D., Reeve, S., Robinson, A., Ehlers, A., Clark, D., Spanlang, B., \& Slater, M. (2017). Virtual reality in the assessment, understanding and treatment of mental health disorders. Psychological Medicine, 1-8. https://doi.org/10.1017/S003329171700040X

Freina, L., \& Ott, M. (2015). A literature review on immersive Virtual Reality in education: State of the art and perspectives. eLearning \& Software for Education, (1).

Fowler, C. (2015). Virtual reality and learning: Where is the pedagogy?. British Journal of Educational Technology, 46(2), 412-422.

Garcia-Palacios, A., Hoffman, H., Carlin, A., Furness III, T.A. \& Botella, C. (2002). Virtual reality in the treatment of spider phobia: A controlled study. Behaviour Research and Therapy, 40, 983-993.

Haniff, D., Chamberlain, A., Moody, L., \& De Freitas, S. (2014). Virtual environments for mental health issues: A review. Journal of Metabolomics and Systems Biology, 3(1), 1-10. https://doi.org/10.5897/ JMSB11.003

Kennedy, R.S., Lane, N.E., Berbaum, K.S., \& Lilienthal, M.G. (1993). Simulator sickness questionnaire: An enhanced method for quantifying simulator sickness. The International Journal of Aviation Psychology, 3(3), 203-220

Kennedy, R.S., Stanney, K.M., \& Dunlap, W.P. (2000). Duration and exposure to virtual environments: Sickness curves during and across sessions. Presence: Teleoperators and Virtual Environments, 9(5), 463-472. https://doi.org/10.1162/105474600566952

Kim, H.K., Park, J., Choi, Y., \& Choe, M. (2018). Virtual reality sickness questionnaire (VRSQ): Motion sickness measurement index in a virtual reality environment. Applied Ergonomics, Vol. 69, 66-73. https://doi. org/10.1016/j.apergo.2017.12.016

Kozlov, M.D., \& Johansen, M.K. (2010). Real behavior in virtual environments: Psychology experiments in a simple virtual-reality paradigm using video games. Cyberpsychology, Behavior, and Social Networking, 13(6), 711-714.
Kubat, U. (2018). Identifying the individual differences among students during learning and teaching process by science teachers. International Journal of Research in Educational and Science, (IJRES), 4(1), 30-38. https://doi.org/10.21890/ijres.369746

LaViola, J.J. (2000). A discussion of cybersickness in virtual environments. ACM SIGCHI Bulletin, 32(1), 47-56. https://doi.org/10.1145/333329.333344

Madary, M., \& Metzinger, T.K. (2016). Real virtuality: a code of ethical conduct. Recommendations for good scientific practice and the consumers of VR-technology. Frontiers in Robotics and Al, 3, 3. https://doi.org/10.3389/frobt.2016.00003

Mantovani, G. (1995). Virtual reality as a communication environment: Consensual hallucination, fiction, and possible selves. Human Relations, 48(6), 669-683. https://doi.org/10.1177/001872679504800604

Markowitz, D.M., Laha, R., Perone, B.P., Pea, R.D., \& Bailenson, J.N. (2018). Immersive Virtual Reality field trips facilitate learning about climate change. Frontiers in Psychology, 9. https://doi.org/10.3389/ fpsyg.2018.02364

O'Keeffe, C. (2019). The psychology of decision-making in critical incidents. In D. Goodwin, and R. Iron (Eds.), The Thinking Leader; Vol. 1 Sandhurst Leadership Series. Havant, Hampshire: Howgate Publishing Limited.

Paton, D. (2006). Critical Incident stress risk in police Officers: Managing resilience and vulnerability. Traumatology, 12(3), 198-206. https://doi. org $/ 10.1177 / 1534765606296532$

Rizzo, A.A., Schultheis, M., Kerns, K.A., \& Mateer, C. (2004). Analysis of assets for virtual reality applications in neuropsychology. Neuropsychological Rehabilitation, 14(1-2 SPEC. ISS.), 207-239. https:// doi.org/10.1080/09602010343000183

Rosenberg, R.S., Baughman, S.L., \& Bailenson, J.N. (2013). Virtual superheroes: Using superpowers in virtual reality to encourage prosocial behavior. PloS One, 8(1), e55003.

Sharples, S., Cobb, S., Moody, A., \& Wilson, J.R. (2008). Virtual reality induced symptoms and effects (VRISE): Comparison of head mounted display (HMD), desktop and projection display systems. Displays, 29(2), 58-69.

Won, A.S., Bailenson, J., Lee, J., \& Lanier, J. (2015). Homuncular flexibility in Virtual Reality. Journal of Computer-Mediated Communication, 3(20), 241-259. 
Yaden, D.B., Iwry, J., Slack, K., Eichstaedt, J.C., Zhao, Y., Vaillant, G.E., \& Newberg, A. (2016). The overview effect: Awe and self-transcendent experience in space-flight. Psychology of Consciousness: Theory, Research, and Practice, 3(1), 1-11. 